\title{
Novel silicone elastomer formulations for DEAPs
}

\author{
Skov, Anne Ladegaard; Vudayagiri, Sindhu; Benslimane, Mohamed
}

\section{Published in:}

Proceedings of SPIE

Link to article, DOI:

$10.1117 / 12.2009465$

Publication date:

2013

Link back to DTU Orbit

Citation (APA):

Skov, A. L., Vudayagiri, S., \& Benslimane, M. (2013). Novel silicone elastomer formulations for DEAPs. In Y.

Bar-Cohen (Ed.), Proceedings of SPIE (Vol. 8687). [86871I] SPIE - International Society for Optical Engineering. https://doi.org/10.1117/12.2009465

\section{General rights}

Copyright and moral rights for the publications made accessible in the public portal are retained by the authors and/or other copyright owners and it is a condition of accessing publications that users recognise and abide by the legal requirements associated with these rights.

- Users may download and print one copy of any publication from the public portal for the purpose of private study or research.

- You may not further distribute the material or use it for any profit-making activity or commercial gain

- You may freely distribute the URL identifying the publication in the public portal

If you believe that this document breaches copyright please contact us providing details, and we will remove access to the work immediately and investigate your claim 


\title{
Novel silicone elastomer formulations for DEAPs
}

\author{
Anne Ladegaard Skov ${ }^{1 *}$, Sindhu Vudayagiri ${ }^{1}$, Mohamed Benslimane ${ }^{2}$ \\ ${ }^{1}$ The Danish Polymer Centre, Department of Chemical and Biochemical Engineering, \\ DTU, 2800 Kgs. Lyngby, Denmark. \\ ${ }^{2}$ Danfoss PolyPower A/S, 6430 Nordborg, Denmark.
}

\begin{abstract}
We demonstrate that the force output and work density of polydimethylsiloxane (PDMS) based dielectric elastomer transducers can be significantly enhanced by the addition of high permittivity titanium dioxide nanoparticles which was also shown by Stoyanov et al[1] for pre-stretched elastomers and by Carpi et al for RTV silicones[2]. Furthermore the elastomer matrix is optimized to give very high breakdown strengths. We obtain an increase in the dielectric permittivity of a factor of approximately 2 with a loading of $12 \% \mathrm{TiO}_{2}$ particles compared to the pure modified silicone elastomer with breakdown strengths remaining more or less unaffected by the loading of $\mathrm{TiO}_{2}$ particles. Breakdown strengths were measured in the range from approximately $80-150 \mathrm{~V} / \mu \mathrm{m}$ with averages of the order of $120-130 \mathrm{~V} / \mu \mathrm{m}$ for the modified silicone elastomer with loadings ranging from 0 to $12 \%$.
\end{abstract}

Keywords: Elastomer, formulations, electrical break down.

\section{INTRODUCTION}

Silicone elastomers have been used in the past as so-called model networks due to their ideal properties in the sense that they are extremely flexible, curing reactions proceed to more or less to $100 \%$ conversion and the resulting elastomers possess little or no micro-crystal domains. Therefore many rubber theories have been evaluated on the basis of silicone elastomers ${ }^{3-8}$. Studies on how to control locally the network structure of the networks have also been performed and revealed that very favorable properties could be obtained compared to the traditional unfilled silicone network which for example possesses very poor tear strength. So-called bimodal networks are prepared by a tedious synthesis procedure where small hyperbranched clusters are allowed to form before allowing the network to form. This reaction schema gives excellent tear strength as well as highly extensible elastomers ${ }^{9-10}$. However, in most commercial elastomer formulations silica particles are used to reinforce the elastomer. The addition of silica particles greatly enhances the tear strength of the silicone but on the other hand it also increases the Young's modulus significantly. The silicone elastomers -both with and without silica fillers- usually have a relative dielectric permittivity around 3 . For the use in dielectric electroactive polymers this value should be increased since the energy density of the elastomer becomes too small for most commercial applications. Therefore a lot of focus has been directed towards the enhancement of the dielectric permittivity without destroying the favorable properties of the silicone elastomer. The research seems to be performed in two categories, namely grafting of high permittivity molecules to the silicone elastomer and mixing in high permittivity inorganic fillers.

The inorganic fillers usually introduce an additional increase in the Young's modulus due to the particle-network interaction. In some cases there is an unfavorable interaction leading to a decrease in the Young's modulus ${ }^{11}$. This should be favorable but what is often encountered is that the unfavorable interactions cause formation of voids which then decrease the tear strength and also influence the electrical breakdown in an unfavorable way. Most favorable

*Tel.: +45252825; Fax: +45882258. E-mail: al@kt.dtu.dk

Electroactive Polymer Actuators and Devices (EAPAD) 2013, edited by Yoseph Bar-Cohen,

Proc. of SPIE Vol. 8687, 86871I · C 2013 SPIE · CCC code: 0277-786X/13/\$18 · doi: 10.1117/12.2009465 
commonly available fillers for the silicones seem to be $\mathrm{TiO}_{2}{ }^{1-2}$ but also the addition of conducting particles below the percolation threshold has shown to be favorable ${ }^{11}$. More exotic fillers such as lead magnesium niobate-lead titanate have also shown promising results ${ }^{12}$.

Also organic molecules have been mixed into the silicone elastomers with a resulting increase in the dielectric permittivity. Carpi et $a l^{13}$ showed a simple blending approach of silicone-poly(hexylthiophene) blends as elastomers with enhanced electromechanical transduction properties. Molberg et al ${ }^{14}$ showed how to encapsulate PANI and then mix it into silicone elastomers.

The grafting approach is more tedious but on the other hand leads to a more controlled network structure which is not relying to the same extent on an efficient mixing procedure which is strictly required for the mixing of particles or organic polymers into the elastomer. Furthermore the grafting should provide more stable systems upon continuous activation of the materials. Risse $e t a l^{15}$ showed that vinyl-functional dipoles could be added to commercial silicones together with a compensating amount of hydride-functional crosslinker and thereby the dielectric permittivity could be increased significantly. Madsen et $a l^{16}$ used a similar approach but with one dipole being specifically grafted on one crosslinker by use of click chemistry. Thereby they could obtain similar results to Risse et al but with amounts of dipoles at least 10 times lower. However, the proposed method of Madsen et al comes with limitations since the concentration of crosslinker is low and thus the dipoles can be added in small amounts only. On the other hand Risse et al introduce the dipoles in a competitive reaction with the crosslinking which then may lead to networks with a significant fraction of network imperfections such as dangling substructures and a so-called sol fraction which can be washed out of the network ${ }^{17}$.

The most well-known silicone in DEAP formulations is the Elastosil RT625 from Wacker Chemie AG. Room temperature vulcanizing (RTV) silicones have favorable properties for processing of thin films due to their relatively low viscosity before mixing. This enables easy mixing in of quite large quantities of e.g. particles. The commercial Liquid Silicone Rubber (LSR) formulations are two-part silicone materials that are mixed and rapidly heat-cured to form elastomeric components. They consist of a two part system with high loadings of $\mathrm{SiO}_{2}$ which leads to the higher viscosities of the premixes compared to the RTV silicones. Furthermore the LSRs may contain peroxides which enables an additional crosslinking mechanism, namely a peroxide initiated crosslinking along the chains rather than of the endfunctional elastomers. The LSRs are also sometimes denoted liquid rubber (LR) silicones. They possess excellent processing performance for injection molding but they are on the other hand difficult to process as thin films due to their very high viscosities. Delebecq et $a l^{18,19}$ have performed a thorough study on the mechanical properties of some commercial available LSR silicones. They showed that the LSR formulations investigated were less influenced by the curing temperature than other types of commercial elastomers such as room temperature vulcanizing (RTV) silicones. A greater freedom of the curing temperature is a very important processing parameter for thin film production. They also conclude that the peroxide cured networks possess poorer compression sets and tensile strength values.

In the following we show that the LSR silicones have very favorable properties as DEAP materials and that further formulation can overcome their limitations in the dielectric permittivity.

\section{Materials and methods}

\section{EXPERIMENTAL}

The following describes the test setup and sample preparation to investigate the quality of the LSR formulations. We have tested 4 different LSR formulations, namely Silastic LC 50-2004 from Dow Corning and three Elastosil LSR formulations (LR 3005/50, 3043/30, and 3043/50) from Wacker Chemie AG. The appropriate amount of Ti0 2 is mixed into the premix without the crosslinker and mixed by use of a Speedmixer for 5 minutes. The two premixes are then 
mixed for another 5 minutes in the Speedmixer. The films are coated with a thin film applicator on a coater bench. For the rheological experiments the thickness of the film is approximately $400-500 \mu \mathrm{m}$, for the breakdown and dielectric permittivity measurements approximately $60-100 \mu \mathrm{m}$.

Rheological characterization of the prepared films was performed with a TA Instruments 2000 Rheometer set to a controlled strain mode at $1 \%$ strain, which was ensured to be within the linear viscoelastic regime. The measurements were performed with parallel plate geometry of $25 \mathrm{~mm}$ at room temperature in the frequency range of $100-0.01 \mathrm{~Hz}$.

Dielectric relaxation spectroscopy (DRS) was performed on a Novocontrol Alpha-A high performance frequency analyzer.

Electrical breakdown strengths were measured on an in-house built device based on international standards. The polymer film $(\sim 60 \mu \mathrm{m})$ was slid between two spherical electrodes and a stepwise increasing voltage was applied (50$100 \mathrm{~V} / \mathrm{step}$ at a rate of $100 \mathrm{~V} / \mathrm{s})$.

\section{RESULTS AND DISCUSSION}

In figure 1 two types of commercially available titanium dioxides dispersed in Silastic LC-50-2004 are evaluated with respect to the resulting electrical breakdown of the elastomers. It can be seen that both types of $\mathrm{TiO}_{2}$ behave in a similar way with more or less no change in the break down (BD) strengths for increased loadings of $\mathrm{TiO}_{2}$ up to approximately 6 $w t \%$. For $9 w t \%$ the BD is increased quite significantly. This is ascribed to the dramatic increase in the Young's modulus of these formulations.

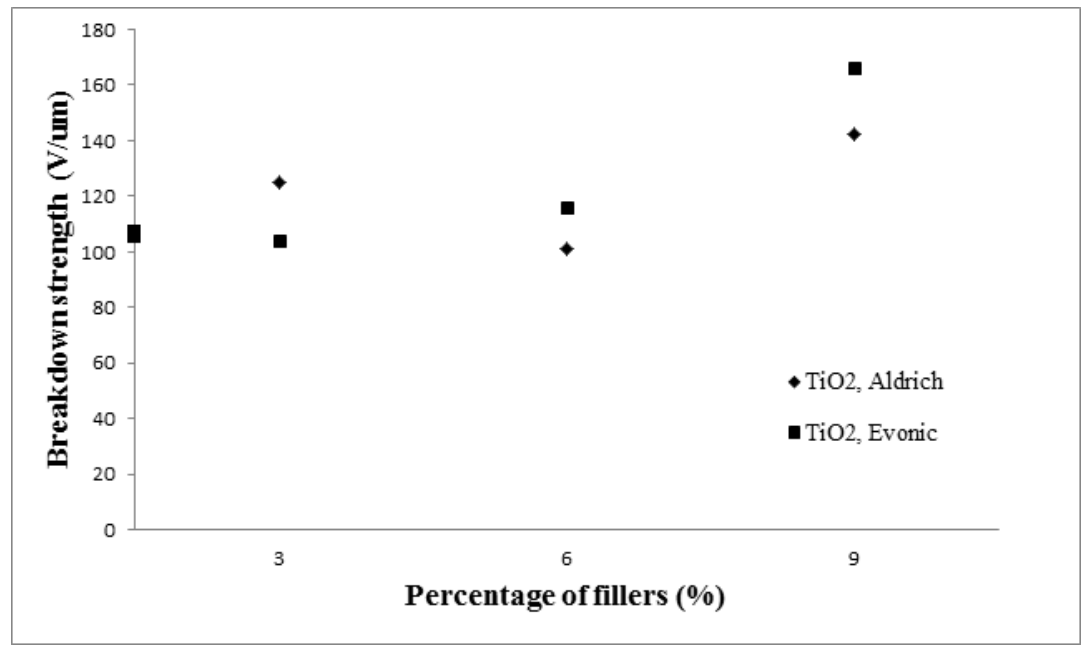

Figure 1: Evaluation of the effect of two types of commercially available titanium dioxide on the electrical breakdown strength for the Silastic LC-50-2004 elastomer.

In figure 2 the dielectric permittivity of the Silastic LR with the two types of titanium dioxide is shown. It can be seen that an increase of the dielectric permittivity of approximately $30 \%$ can be obtained by the addition of $6 \mathrm{wt} \% \mathrm{TiO}_{2}$ (Evonik). For this formulation the film properties are excellent. The increase is slightly less than expected compared to previous results for silicones with lower viscosities but this is probably due to a combined effect of interference from the high loadings of silica particles in the LSR formulations as well as problems with ensuring proper dispersion of the 
$\mathrm{TiO}_{2}$. The latter effect is observed clearly for the formulations with $9 \mathrm{wt} \% \mathrm{TiO}_{2}$ for the Aldrich $\mathrm{TiO}_{2}$ where the dielectric permittivity suddenly drops. This indicates that there is less accessible surface area despite higher loadings, i.e. that the particles agglomerate. The films of Silastic with $12 \%$ loadings also become very rough and the measurements of the film thickness may be inaccurate. This strongly influences the dielectric permittivity measurements. Based on the results from the electrical breakdown strengths and the dielectric permittivity it was decided to focus on the Evonik titanium dioxide for the further studies. The two brands behaved very similar within experimental uncertainty at low loadings but the Evonik $\mathrm{TiO}_{2}$ was easier to disperse properly at higher loadings.

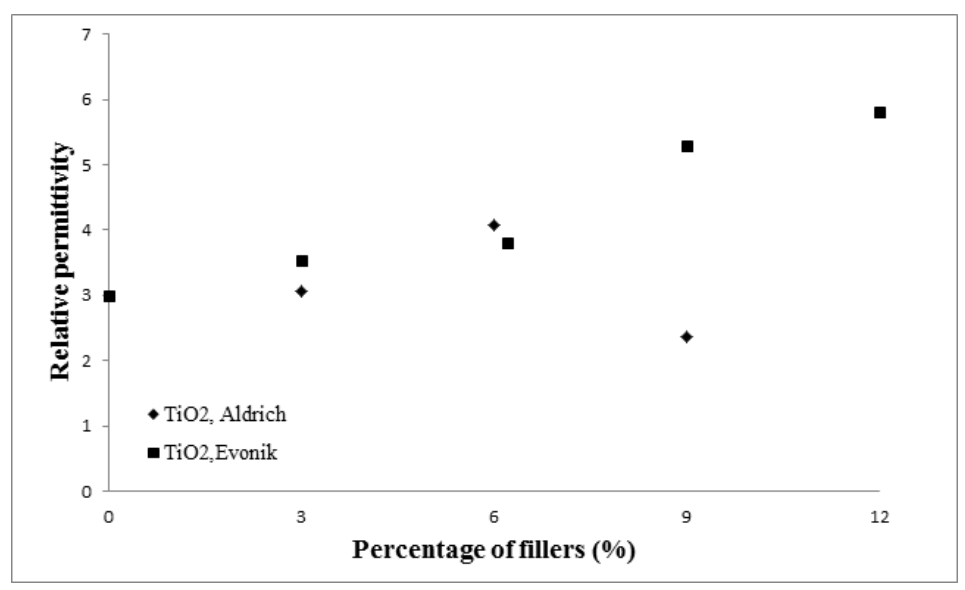

Figure 2: The dielectric permittivity of the Silastic LC-50-2004 elastomer with the two commercially available titanium dioxides.

Different types of LSR elastomers were evaluated with respect to their rheological properties and dielectrical breakdown strengths. The Young's moduli at room temperature of the unfilled elastomers are given in table 1. Seen from a rheological point of view the 4 formulations vary significantly. LR 3005/50 and LR3043/30 are the softest and are identical in terms of the Young's moduli in their so-called linear regime, i.e. for strains approaching zero (for silicones the general linear viscoelastic regime are up to $10 \%$ strain $)^{20}$. Silastic LC-50-2004 requires significantly higher forces, and the LR3043/50 requires the double force for elongation of the two softest LSRs.

Table 1: The Young's moduli of the investigated LSR silicone elastomers.

\begin{tabular}{|l|c|}
\hline Name & Y [kPa] \\
\hline Silastic LC-50-2004 & 330 \\
LR 3005/50 & 280 \\
LR3043/30 & 280 \\
LR3043/50 & 536 \\
\hline
\end{tabular}




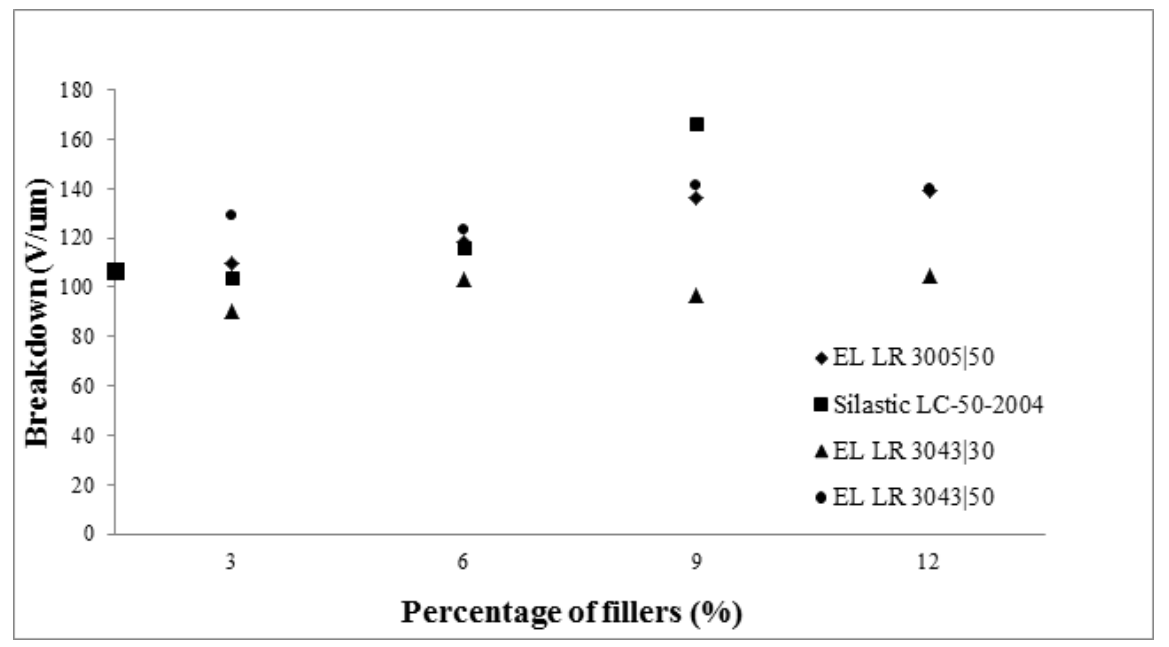

Figure 3: The breakdown strengths of four types of LSR elastomers with different loadings of Evonik titanium dioxide.

In figure 4 the BDs of four LSRs are shown. The BD of pure LSRs arrange as expected with the hardest material (LR3043/50) having the highest BD and (LR3043/50) having the lowest. The BDs range from approximately 90-130 $\mathrm{V} / \mu \mathrm{m}$. When filler $\left(\right.$ Evonik $\left.\mathrm{TiO}_{2}\right)$ is added the BDs are increased slightly until as observed earlier that a decrease is observed for all but the LR3043/30 between 9 and $12 \mathrm{wt} \%$.

Furthermore a so-called core-shell morphology type of filler (Stx801 from Evonik) was investigated in combination with several of the LSR elastomers. The core consists of $\mathrm{TiO}_{2}$ and the shell of $\mathrm{SiO}_{2}$. The improvement in the dielectric permittivity was limited to a few percent at loadings of 3-6 wt \%, and the particles were strongly reinforcing, thus also leading to a favorable increase in the electrical breakdown strengths as can be seen in figure 4 . The Stx801 particles cause BD approximately $20 \mathrm{~V} / \mu \mathrm{m}$ higher than the corresponding regular $\mathrm{TiO}_{2}$ particle loadings.

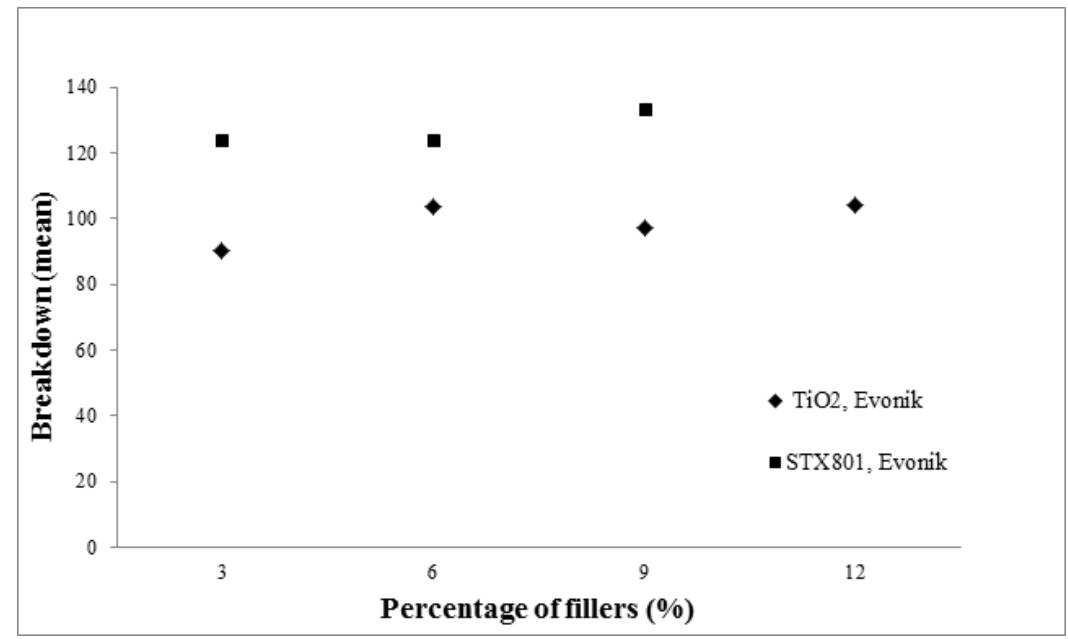

Figure 4: LR3043/30 with the core-shell morphology $\mathrm{TiO}_{2}-\mathrm{SiO}_{2}$ filler from Evonik (Stx801).

The requirements for fillers to the LSR compositions are strict due to the very high viscosities of the LSR compositions such that the fillers first of all should be relatively easy to disperse in the highly viscous silicone without the requirement for a lot of additional solvent. 
The best candidate of the pure LSRs with respect to BD was the LR3043/50 due to its high Young's modulus. The figure of merit defined of Sommer-Larsen ${ }^{21}, \mathrm{~F}_{\mathrm{om}}=\varepsilon^{*} \mathrm{BD}^{2} / \mathrm{Y}$ can therefore be improved significantly for this formulation. $\mathrm{F}_{\text {om }}$ compared to Elastosil RT625 will for example be $\mathrm{F}_{\mathrm{om}}=3 / 3 *(130 / 60)^{2} /(540 / 300)=2.6$. In the filled formulation the $\mathrm{F}_{\text {om }}$ compared to the filled Elastosil is less than $3 / 3.3 *(120 / 60)^{2} /(540 / 300)=2$. The actuation is not improved as the dielectric permittivity would have to be increased by at least a factor of 2 to compensate for the increased Young's modulus, which furthermore would increase additionally with higher loadings.

\begin{tabular}{|l|l|l|}
\hline $\begin{array}{l}\text { Best candidate } \\
\text { with respect to: }\end{array}$ & $\mathrm{F}_{\mathrm{om}} / \mathrm{F}_{\mathrm{om}}(625)$ & $\begin{array}{c}\text { Improved actuation } \\
\text { (relative to Elastosil } \\
\text { RT625) }\end{array}$ \\
\hline $\begin{array}{l}\text { Simplicity of } \\
\text { formulation } \\
\text { LR3043/50 }\end{array}$ & 2.6 & negative \\
\hline $\begin{array}{l}\text { Improved } \\
\text { actuation }\end{array}$ & 3.0 & 7.8 \\
\hline
\end{tabular}

The improved actuation is, however, only shown for formulations with Silastic and high loadings (12 wt $\%)$ of $\mathrm{TiO}_{2}$ where it is estimated that the improvement in actuation compared to unfilled Elastosil RT625 is $\varepsilon / \mathrm{Y}=$ $5.8 / 3 /(450 / 300)=1.3$ and with a simultaneous improvement of the figure of merit to $\mathrm{F}_{\mathrm{om}}=5.8 / 3 *(170 / 60)^{2} /(600 / 300)=7.8$.

\section{CONCLUSION}

It is shown that the commercially available LSR silicones hold great properties for the future EAP materials, especially when loaded with $\mathrm{TiO}_{2}$. The formulated elastomers possess very high electrical breakdown strengths compared to the commonly used RTV silicones. With respect to the improved actuation the LSR formulations encounter problems with high Young's moduli and therefore are most suitable for generator purposes. A slight increase in the actuation was obtained but the power of the LSR formulations was shown to be their figure of merits where they easily improved a factor of 7 compared to RTVs.

It is believed that it is possible to increase the dielectric permittivity further without compromising the BD from the optimization of the mixing schemes, and that the LSR silicones possess a lot of novel promising features for the future, especially as materials for generator applications.

\section{ACKNOWLEDGMENT}

The authors wish to acknowledge the Danish National Advanced Technology Foundation for financial support.

\section{REFERENCES}

1. Stoyanov, H., Brochu,P., Niu, X., Gaspera, E.D., and Pei, Q., "Dielectric elastomer transducers with enhanced force output and work density," Appl. Phys. Lett. 100, 262902 (2012).

2. Carpi, F. and De Rossi, D., "Improvement of electromechanical actuating performances of a silicone dielectric elastomer by dispersion of titanium dioxide powder," IEEE Transactions on Dielectrics and Electrical Insulation. DOI: 10.1109/TDEI.2005.1511110, 12 (4), 835-843 (2005). 
3. Hansen, R., Skov A. L. and Hassager, O. "Constitutive Equation for Polymer Networks with Phonon Fluctuations,” Phys. Rev. E 77, 011802 (2008).

4. Mark, J.E. and Curro, J.G., "A non-Gaussian theory of rubberlike elasticity based on rotational isomeric state simulations of network chain configurations. I. Polyethylene and polydimethylsiloxane short-chain unimodal networks," J. Chem. Phys. 79, 5705 (1983).

5. Urayama, K., Kawamura, T. and Kohjiya, S., "Structure-mechanical property correlations of model siloxane elastomers with controlled network topology," Polymer 50, 347-356 (2009).

6. Jensen, M.K., Hassager, O., Rasmussen, H.K., Skov, A.L., Bach, A. and Koldbech, H., "Planar Elongation of Soft Polymeric Networks," Rheologica Acta 49(1), 1-13 (2010).

7. Bejenariu, A.G., Rasmussen, H.K., Skov, A.L., and Hassager, O., "Large Amplitude Oscillatory Extension of Soft Polymeric Networks," Rheologica Acta 49(8), 807 (2010).

8. Marcelo A. Villar, Miguel A. Bibbo, and Enrique M. Valles, "Influence of Pendant Chains on Mechanical Properties of Model Poly(dimethylsiloxane) Networks.1.Analysis of the Molecular Structure of the Network," Macromolecules 9297(95), 4072-4080 (1996).

9. Galiatsatos, V. and Mark, J.E., "Non-Gaussian optical properties of bimodal elastomeric networks," Macromolecules 20 (10), 2631-2632 (1987).

10. Bejenariu, A.G., Yu, L. and Skov, A.L., "Low moduli elastomers with low viscous dissipation," Soft Matter 8(14), 3917-3923 (2012).

11. Daugaard A.E., Hassouneh, S.S., Kostrzewska, M., Bejenariu, A.G., Skov, A.L., "High dielectric permittivity elastomers from well-dispersed expanded graphite in low concentrations", in Proceedings of SPIE 2013, ibid.

12. Gallone, G., Carpi, F. and De Rossi,D., et al. "Dielectric constant enhancement in a silicone elastomer filled with lead magnesium niobate-lead titanate," Materials Science \& Engineering C-Biomimetic \& Supramolecular systems 27(1), 110-116 (2007).

13. Carpi, F., Gallone, G., Galantini, Fabia; et al."Silicone-Poly (hexylthiophene) Blends as Elastomers with Enhanced Electromechanical Transduction Properties," Advanced Functional Materials 18(2), 235-241 (2008).

14. Molberg, M., Crespy, D., Rupper, P., Nüesch, F., Jan-Anders E. M., Löwe, C., and Opris, D.M., "High Breakdown Field Dielectric Elastomer Actuators Using Encapsulated Polyaniline as High Dielectric Constant Filler," Advanced Functional Materials 20(19), 3280-3291 (2010).

15. Kussmaul, B., Risse, S., Kofod, G., Wache, R., Wegener, M., McCarthy, D.N., Krüger, H. and Gerhard, R.,"Enhancement Of Dielectric Permittivity And Electromechanical Response In Silicone Elastomers: Molecular Grafting Of Organic Dipoles To The Macromolecular Network," Advanced Functional Materials 21(23), 4589-4594 (2011).

16. Madsen, F.B., Dimitrov,I., Daugaard, A.E., Hvilsted, S. and Skov, A.L. "Novel cross-linkers for PDMS networks for controlled and well distributed grafting of functionalities by click chemistry," Polymer Chemistry 4 (5), 1700- 1707 (2013). 
17. Frankær, S.M.G., Jensen, M.K., Bejenariu, A.G. Skov, A.L.: 'Investigation of the properties of fully reacted unstoichiometric polydimethylsiloxane networks and their extracted network fractions', Rheologica Acta 51(6), 559-567 (2012).

18. Delebecq, E. and Ganachaud, F. "Looking over Liquid Silicone Rubbers: (1) Network Topology vs Chemical Formulations," ACS Appl. Mater. Interfaces 4 (7), 3340-3352 (2012).

19. Delebecq, E., Hermeline, N., Flers, A. and Ganachaud, F. "Looking over Liquid Silicone Rubbers: (2) Mechanical Properties vs Network Topology," ACS Appl. Mater. Interfaces 4 (7), 3353-3363 (2012).

20. Larsen, A.L., Hansen, K., Sommer-Larsen, P., Hassager, O., Bach, A., Ndoni, S., Jørgensen, M.: "Elastic Properties of Nonstoichiometric Reacted PDMS Networks", Macromolecules 36, 10063 (2003).

21. Sommer-Larsen P, Larsen, A.L.: "Materials for dielectric elastomer actuators", in SPIE Proceeding 5385, 6877 (2004). 